\title{
VARIATION IN ERYTHROCYTE ENZYME ACTIVITY AMONG PRIMATE SPECIES
}

\author{
T. R. TURner, P. T. Wade and H. W. MOHRENWEISER \\ Department of Human Genetics, University of Michigan Medical School, Ann Arbor, MI 48109, USA
}

(Tel: 764-5490)

(Received 26 July 1983)

\begin{abstract}
Significant differences between species in the mean level of enzyme activity, ranging from 50 to $400 \%$, were detected during a study of 10 enzymes from erythrocytes of humans and five non-human primates.

2. The activity differences were consistent with variation, between species, at the structural loci for specific enzymes rather than differences in mean cell age, hemoglobin content or other pleiotropic effects.

3. For seven of the eight loci at which direct comparisons among the six species could be made, the number of species-specific activity differences was greater than the number of variants observed by electrophoresis.

4. Thus not only do activity measurements detect previously "hidden" variation among species but they also provide information regarding genetic differences which may be of potential physiological and/or selective relevance.
\end{abstract}

\section{INTRODUCTION}

Non-human primates, because of their significance in biomedical and anthropological research have been the subjects for numerous investigations into their genetic composition, with most studies utilizing electrophoretic techniques. With the exception of the glucose-6-phosphate dehydrogenase activity studies by Barnicot and Cohen (1970) and the studies of carbonic anhydrase activity by Tashian (1977) relatively little information is available on the comparative enzymology of erythrocytes from non-human primates. This is in stark contrast to our information from many other species including sheep (Agar et al., 1975b,c) rabbit (Agar and Smith, 1974) cattle (Agar et al., 1975a) dog (Smith and Kiefer, 1973) marsupials (Agar et al., 1976) and others (Smith et al., 1965; Harvey and Kaneko, 1975). Since primates are often selected as medical models, particularly for studies in oncology, arteriosclerosis and reproduction, it is of particular interest and value to define the range of variability which may be encountered, with emphasis on parameters of functional significance.

Variation manifested as a deviation from "normal" enzyme activity level is a class of "hidden" variation with a probability of being of physiological importance. The genetic basis for variation in erythrocyte enzyme activity levels has been well established with approximately $50 \%$ of the loci in humans identified as polymorphic by electrophoresis having significant differences between the different allelic forms in the levels of activity in erythrocytes (Harris, 1971; Modiano, 1976); the most studied examples are glucose-6-phosphate dehydrogenase, (Morelli et al., 1978) and erythrocyte acid phosphatase (Eze et al., 1974; Spencer et al., 1974). Other enzymes, such as glutathione peroxidase, however, exhibit polymorphic variation in activity without corresponding electrophoretic mobility shifts (Beutler and Mat- sumoto, 1975). A subset of the activity variants, which are not associated with mobility shifts, are the deficiency or "null" alleles. These are usually rare, although some exist in polymorphic frequency in the human population (Mohrenweiser, 1981; Mohrenweiser and Fielek, 1982). Homozygosity for null alleles is often associated with the disease conditions which are collectively referred to as metabolic errors. These rare "null" alleles, exist at higher cumulative frequencies in human populations than do rare electrophoretic alleles (Mohrenweiser and Neel, 1981). Thus, the various categories of activity variants, including the null variants, can be important components of studies which seek to define the total amount of genetic variation between and within populations.

In this study we have attempted to begin this process of defining the range of genetic variation among primate species by an examination of erythrocyte enzyme activity differences among human and five species of non-human primates. The six species separate into three groups, the hominoids (human and chimpanzee), the baboon-rhesus pair and the vervet-patas pair. While the monkeys are all members of the Cercopithecoidea, the baboons and rhesus are more closely related to each other phylogenetically than they are to the vervets and the patas (Napier and Napier, 1967).

\section{MATERIALS AND METHODS}

Twelve individuals from each of five species of nonhuman primates were examined. All the individuals were adults. The sample was equally divided between males and females. The baboons (Papio anubis), rhesus (Macaca mulatta), and the chimpanzees (Pan paniscus), are all members of colonies housed at the Laboratory for Experimental Medicine and Surgery in Primates (LEMSIP) in Tuxedo, New York. The vervet monkeys (Cercopithecus aethiops) were wild caught and are currently housed as members of a breeding colony at the Institute for Primate Research 
Table 1. Levels of enzyme activity in erythrocytes from six primate species

\begin{tabular}{|c|c|c|c|c|c|c|}
\hline \multirow[b]{2}{*}{ Enzyme } & Human & Chimpanzee & Baboon & Rhesus & Vervet & Patas \\
\hline & \multicolumn{6}{|c|}{ (Units of activity per $g$ hemoglobin \pm S.D.) } \\
\hline AK & $11,840 \pm 1220$ & $7210 \pm 1020$ & $5075 \pm 890$ & $3390 \pm 620$ & $7060 \pm 1390$ & $3970 \pm 1010$ \\
\hline DPGM & $2345 \pm 350$ & $1130 \pm 280$ & $1925 \pm 390$ & $1550+280$ & $1105+190$ & $1185 \pm 305$ \\
\hline ENOL & $570 \pm 75$ & $565 \pm 135$ & $540 \pm 140$ & $450 \pm 160$ & $455 \pm 170$ & $680 \pm 150$ \\
\hline G6PD & $227 \pm 40$ & $226 \pm 108$ & $81 \pm 14$ & $112 \pm 16$ & $172 \pm 50$ & $159 \pm 47$ \\
\hline GPI & $2510 \pm 325$ & $4715 \pm 875$ & $9890 \pm 1890$ & $5745 \pm 550$ & $5155 \pm 840$ & $5700 \pm 1130$ \\
\hline GR & $710 \pm 130$ & $435 \pm 60$ & $370 \pm 90$ & $325 \pm 90$ & $375 \pm 65$ & $380 \pm 65$ \\
\hline $\mathrm{LDH}$ & $10,180 \pm 1220$ & $10,795 \pm 2140$ & $7560 \pm 1425$ & $8660 \pm 1815$ & $5060 \pm 780$ & $9145 \pm 1730$ \\
\hline MDH & $7860 \pm 2380$ & $13,500 \pm 2125$ & $5170 \pm 1465$ & $4520 \pm 995$ & $9550 \pm 2250$ & $5540 \pm 860$ \\
\hline PGK & $7100 \pm 1540$ & $7150 \pm 1760$ & $9150 \pm 1275$ & $9850 \pm 2210$ & $4260 \pm 1145$ & $8135 \pm 1285$ \\
\hline PK & $926 \pm 180$ & $855 \pm 135$ & $2295 \pm 480$ & $4135 \pm 670$ & $1265 \pm 260$ & $2505 \pm 480$ \\
\hline TPI & $139,500 \pm 26,880$ & $40,660 \pm 7535$ & $71,415 \pm 26,090$ & $46,100 \pm 10,050$ & $43,870 \pm 18,250$ & $57,790 \pm 22,670$ \\
\hline
\end{tabular}

(IPR) in Limuru, Kenya. The patas monkeys (Erythrocebus patas) are members of a colony at the Caribbean Primate Research Center in Puerto Rico. Blood samples from all of these animals have been previously examined by electrophoresis at the Laboratory of Physical Anthropology, New York University. Samples from two of the species included in this survey (vervet monkey and patas) have been the subject of a population survey for genetic variation (Dracopoli et al., 1983). No electrophoretic variation within a species was detected at any of the loci studied in this report. Human samples were collected from laboratory personel.

Within four hours of drawing the blood, the samples were centrifuged and the red cells washed four times in physiological saline before the packed red cells were stored in liquid $\mathrm{N}_{2}$, thus all samples were handled uniformly and were of excellent quality. The preparation of hemolysates and electrophoretic techniques utilized in the current study were as previously described (Neel et al., 1980).

The following enzymes: adenylate kinase (AK, E.C. 2.7.4.3), diphosphoglyceromutase (DPGM, E.C. 2.7.5.3), enolase (ENOL, E.C. 4.2.1.11), glucose-6-phosphate dehydrogenase (G6PD, E.C. 1.1.1.49), glucosephosphate isomerase (GPI, E.C. 5.3.1.9), glutathione reductase (GR, E.C. 1.6.4.2), lactate dehydrogenase (LDH, E.C. 1.1.1.27), malate dehydrogenase (MDH, E.C. 1.1.1.37), phosphoglycerokinase (PGK E.C. 2.7.2.3), pyruvate kinase (PK, E.C. 2.7.1.40) and triosephosphate isomerase (TPI, E.C. 5.3.1.1) were assayed as previously described by Fielek and Mohrenweiser (1979) Mohrenweiser (1981) and Mohrenweiser and Fielek (1982). The analytical design consisted of single determinations per enzyme per individual with two animals per species grouped together in each set of determinations (Fielek and Mohrenweiser, 1979). Substrate levels were at least four times $K_{m}$ values for the human isozyme for all quantitative assays. The units of activity are $\mu$ moles product per gramme hemoglobin per hour at $30^{\circ} \mathrm{C}$

\section{RESULTS}

The mean and standard deviation of the activity level for each of 11 enzymes, by species, is given in Table 1 . The standard deviations are generally comparable in all groups. The small differences among members of a species could not be correlated with the sex of the individual.

Figure 1 graphically depicts these differences in activity levels. Each enzyme is represented by a vertical line; the species with the highest activity level is designated $100 \%$ and the means of the other species are designated as a percentage of this level of activity.

It is immediately apparent that there is great variability in the mean level of erythrocyte enzyme activity among species, with some species exhibiting three to four times the activity level of other species. There is however, no apparent pattern in these activ- ity differences as no species is always high or low in its enzyme activity level.

Each species is represented at least once in the highest and lowest activity groupings although human is the most frequent representative in the high group and vervet is the most frequent representative of the low activity group. Even within enzymes of the same metabolic pathway no pattern of high or low activity is detectabie. Also the activity pattern is not consistent with significant differences in sample quality nor is the profile similar to that observed in human blood samples with an increased percentage of reticulocytes or a reduced mean cell age.

The least variation among the species in level of enzymatic activity is observed for ENOL where patas has the highest level of activity and rhesus and vervet are the lowest, with approximately $70 \%$ of the ENOL activity level of patas erythrocytes. The other three species, human, chimpanzee and baboon, had intermediate levels of ENOL activity. The erythrocyte LDH activity ranges from 55 to $100 \%$. The $\mathrm{LDH}$ activity profile displays the least clustering among species of any of the enzymes. The levels of PGK and

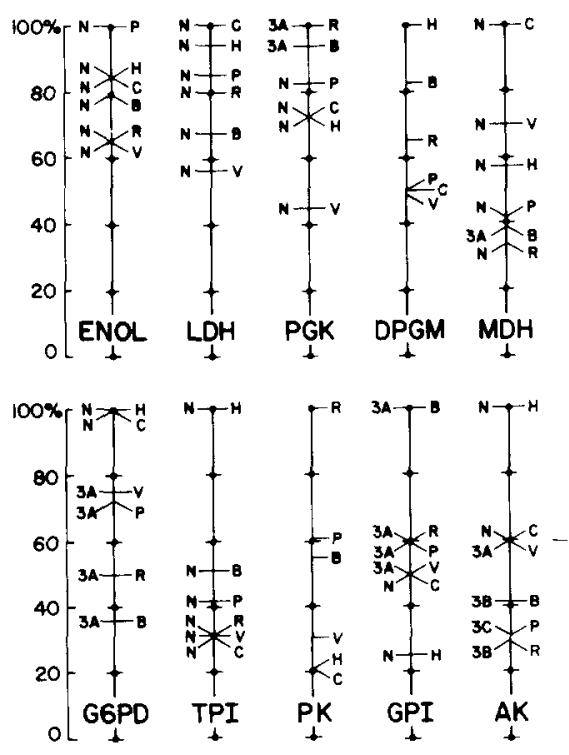

Fig. 1. Relative levels of erythrocyte enzyme activity among primate species. The activity is expressed as a percentage of the highest activity species. The species designations--to the right of the vertical axis - are: $\mathrm{B}$ baboon, $\mathrm{C}$ chimpanzee, $\mathrm{H}$ human, $\mathrm{P}$ patas, $\mathrm{R}$ rhesus and $\mathrm{V}$ vervet. The relative electrophoretic mobility of the enzyme from each species is to the left of the species designation and is from Fig. 2. 


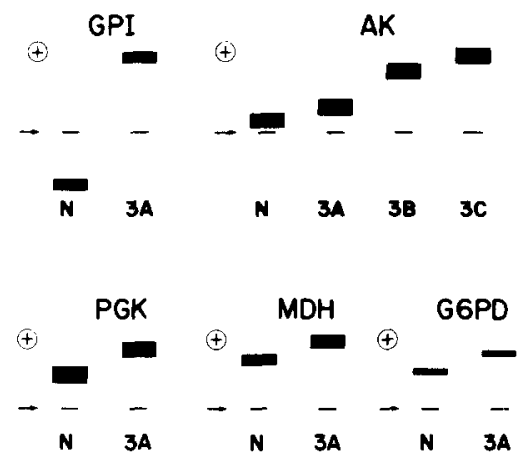

Fig. 2. Schematic diagram of electrophoretic mobilities for erythrocyte enzymes from several primate species. Only the primary isozyme is shown. The variant designations are described in the text.

DPGM activity cover a 55 percentage-point range and three clusters are identifiable for each enzyme. The difference between the highest and lowest activity species is approximately 70 percentage points for $\mathrm{MDH}, \mathrm{G} 6 \mathrm{PD}$ and TPI. Three activity groups are evident for MDH and G6PD while for TPI, the major difference in enzyme activity is noted between human and non-human primates. The largest differences in enzymatic activity are seen for PK, GPI and AK with 4-fold differences in activity for these three enzymes; the six species can be divided into three groups on the basis of activity levels for each of these enzymes.

One other enzyme, glutathione reductase, was also assayed. Two activity classes are observed with humans having the highest activity and all of the non-human primates clustered together at $50 \%$ of the activity in erythrocytes from humans. Although this activity difference could be associated with genetic variation, it is important to note that riboflavin nutritional status has a key role in determining the level of GR activity (Glatzle et al., 1974; Beutler, 1979). Given the possibility of a nutritional rather than a genetic basis for the activity differences for this enzyme, GR is not included in our estimates of the number of activity variants.

Electrophoretic comparisons were conducted for eight of the 10 enzymes studied for genetic variation with quantitative techniques. The electrophoretic profiles for these enzymes are represented schematically in Fig. 2. The human enzyme is designated as the normal phenotype and isozymes with less anodal mobility are designated $2 \mathrm{~A}, 2 \mathrm{~B}$, etc. while isozymes with greater anodal mobilities, relative to the human isozyme, are designated $3 \mathrm{~A}, 3 \mathrm{~B}$, etc. The electrophoretic phenotype for each species is shown along with the activity level in Fig. 1. The enzymes, ENOL, TPI and LDH had similar electrophoretic mobilities in all six species while for four other enzymes, (PGK, MDH, G6PD and GPI) two mobility classes were detected. Four electromorphs were observed for AK. The enzymes from human and chimpanzee have similar mobility in each instance and differ from the other species for GPI, and G6PD while PGK in baboon and rhesus has a different mobility than the enzyme in the other species. In only two instances, patas/vervet for $\mathrm{AK}$ and baboon/rhesus for MDH do the closely related members of a pair exhibit different electromorphs.
Table 2. Estimation of the number of variants identified in six primate species Number of Number of Total activity electrophoretic number of

\begin{tabular}{|c|c|c|c|}
\hline Enzyme & classes & classes & variants \\
\hline AK & 3 & 4 & 5 \\
\hline DPGM & 4 & * & 4 \\
\hline ENOL & 3 & 1 & 4 \\
\hline G6PD & 3 & 2 & 3 \\
\hline GPI & 3 & 2 & 4 \\
\hline $\mathrm{LDH}$ & 3 & 1 & 3 \\
\hline $\mathrm{MDH}$ & 3 & 2 & 4 \\
\hline PGK & 3 & 2 & 3 \\
\hline PK & 3 & * & 3 \\
\hline TPI & 2 & 1 & 2 \\
\hline Average & 3.0 & 1.9 & 3.5 \\
\hline Total & & & 35 \\
\hline
\end{tabular}

*These enzymes were not studied with electrophoretic techniques.

For eight of the enzymes, it is possible to examine the species specific variation for both activity and electrophoretic mobility. The mobility of PGK in rhesus and baboon, the two species with the highest PGK activity differed from the mobility of the enzyme in the other species. Similar results were observed for G6PD except that the high activity species were humans and chimpanzees. The mobility of $\mathrm{MDH}$ in baboons differed from the other species but it was one of three species with activity levels at $40 \%$ of the activity in erythrocytes from chimpanzees. Four electrophoretic mobility classes were observed for AK but again they did not consegregate with the four enzyme activity classes.

An estimate of the total number of species specific variants existing among the six species is presented in Table 2. With the exception of AK, the number of groups identified by quantitative techniques is greater than the number of mobility classes identified with standard electrophoretic techniques. And in fact, combining activity measurements with electrophoretic techniques suggests that almost twice as many variants exist as expected from the electrophoretic studies alone.

\section{DISCUSSION}

Variation in natural populations is the basis of evolution, providing the raw material upon which the processes of natural selection and random genetic drift operate. Traditionally, genetic variation within and among populations has been assessed by electrophoretic analysis of blood proteins. However, this technique underestimates the actual amount of genetic variability in populations since only charge change variants are recognized. Recently, thermostability determinations as well as electrophoresis using gradient acrylamide gels, multiple buffer systems, and isoelectric focusing techniques have identified variation which was not detected with "standard" electrophoretic techniques. (Johnson, 1974; Coyne and Felton, 1977; Kuhnl et al., 1977; Bonhomme and Selander, 1978; Satoh and Mohrenweiser, 1979; Wurzinger and Mohrenweiser, 1982).

Enzyme activity variants provide an additional means of studying variation within and between primate species. The level of enzymatic activity in a 
cell, in the absence of a significant change in $K_{m}$, is a direct reflection of the quantity of functional enzyme protein, which in turn is the result of the balance between the rate of synthesis and the rate of degradation of the protein. In the enucleated erythrocyte only the rate of degradation of the enzyme and the half life of the cell are factors. Thus, differences in mean erythrocyte age and/or the percentage of reticulocytes in the blood sample can alter the levels of enzymatic activity. A reduction in mean cell age or an increased reticulocyte content will result in an increase in the activity for most enzymes with PK and G6PD exhibiting the largest deviations rather than the specific variation observed in this study (Barthelmai and Vetrella, 1973; Komazawa and Oski, 1975; Mohrenweiser et al., 1981). This pattern of increased activity for most enzymes associated with differences in the distribution cell types may reflect either a polygenic trait, the pleiotropic effect of a major locus (Miwa et al., 1980) or an environmental influence (Boivin et al., 1975; Kahn et al., 1976). No evidence of this type of activity profile was observed for any of the species in this study. Changes involving the structural locus or the flanking regions, and which alter the rate of synthesis or degradation of an enzyme or the specific activity of an enzyme will not yield a pattern observed in dyserythropoietic conditions (Boivin, 1977) but will result in the types of enzyme activity profiles observed among the species in this study. Thus, it seems reasonable to suggest that the species specific variation observed, reflects genetic variation at the structural locus (or flanking and/or intervening regions) for each of these enzymes.

The diversities in enzymatic activities among the six primate species are at least as large as observed in similar comparisons of red cell enzymes in diverse species. At present, we believe that the up to four fold range of variation which exists among these species, which are phylogenetically similar, is a reflection of genetic differences at or near the structural locus for each of these enzymes although additional studies will be necessary to confirm this suggestion. Inclusion of this quantitative variation increases the apparent genetic differences among these species by a factor of approximately two over the variation observed with electrophoretic techniques alone. Additionally, some of the quantitative differences are of sufficient magnitude to be potentially physiologically significant especially when these primate species are used as models for human disease conditions, drug therapy or other metabolic and/or physiological responses.

Acknowledgements-Financial support was derived from contract EY-77-C-02-2828 from the Department of Energy and from $\mathrm{NIH}$ training grant, T-32GM07123. The assistance of $\mathrm{T}$. Krastoff and $\mathrm{K}$. H. Wurzinger with the electrophoretic studies is appreciated as were the helpful discussions with Dr. D. Hewett-Emmett. Non-human primate samples were supplied by Dr. E. Mutchmore of LEMSIP and Dr. C. J. Jolly of New York University.

\section{REFERENCES}

Agar N. S. and Smith J. E. (1974) Enzymes and glycolytic intermediates in the rabbit erythrocytes. Enzyme 17, 205-209.
Agar N. S., Gruca M. A., Dunbar J. and Harley J. D. (1975a) Red cell enzymes I. Glycolytic enzymes and reduction of glutathione in bovine red blood cells. Comp. Biochem. Physiol. 51B, 463-466.

Agar N. S., Gruca M. A., Harley J. D. and Roberts J. (1975b) Red cell enzymes--II. Enzyme activities in the red blood cells of high and low potassium sheep. Comp Biochem. Physiol. 51B, 467-469.

Agar N. S., Gruca M. A., Harley J. D. and Roberts J. (1975c) Red cell enzymes-III. Enzyme activities in the red blood cells of different breeds of sheep. Comp. Biochem. Physiol. 51B, 71-473.

Agar N. S., Gruca M. A., Mulley A., Stephens T, and Harley J. D. (1976) Red cell enzymes-IV. A comparative study of red blood cells from various species of marsupials in Australia. Comp. Biochem. Physiol. 53B, 455-460.

Barnicot N. A. and Cohen P. (1970) Red cell enzymes of primates (Anthropoideas). Biochem. Genet. 4, 41-57.

Barthelmai W. and Vetrella M. (1973) Activities of erythrocyte enzymes through fetal and postnatal life. In Current Aspects Perinatal Physiol. Child (Edited by Linneweh F.) pp. 71-82. Springer, Berlin.

Beutler E. (1979) Red cell enzyme defects as nondiseases and diseases. Blood 54, 1-7.

Beutler E. and Matsumoto F. (1975) Ethnic variation in red cell glutathione peroxidase activity. Blood 46, 103-110.

Boivin P. (1977) Red cell enzyme abnormalities. In Dyserythropoietic Anaemias (Edited by Lewis S. M. and Verwilghen R. L.), pp. 221-246. Academic Press, New York.

Boivin P., Galand C., Hakim J. and Kahn A. (1975) Acquired erythroenzymopathies in blood disorders. $B r . J$. Haemat. 31, 531-543.

Bonhomme F. and Selander R. K. (1978) Estimating total genic diversity in the house mouse. Biochem. Genet. 16, 287-297.

Coyne J. and Felton A. A. (1977) Genic heterogeneity at two alcohol dehydrogenase loci in Drosophilia pseudoobscura and Drosophila persimilis. Genetics 8, 285-304.

Dracopoli N. C., Brett F. L., Turner T. R. and Jolly C. J. (1983) Patterns of genetic variability in the serum proteins of the Kenyan vervet monkey (Cercopithecus aethiops). Am. J. Phys. Anthrop. 61, 39-50.

Eze L. C., Tweedie M. C. K., Bullen M. F., Wren P. J. J. and Evans D. A. P. (1974) Quantitative genetics of human red cell acid phosphatase. Ann. Hum. Genet. Lond. 37 , 333-340.

Fielek S. and Mohrenweiser H. W. (1979) Erythrocyte enzyme deficiencies assessed with a miniature centrifugal analyzer. Clin. Chem. 25, 384-388.

Glatzle D., Vuilleumier J. P., Weber F. and Decker K (1974) Glutathione reductase test with whole blood. A convenient procedure for the assessment of the riboflavin status in humans. Experientia 30, 665-667.

Harris H. (1971) Polymorphism and protein evolution: the neutral mutation-random drift hypothesis. J. med. Genet. 8, 444-452.

Harvey J. W. and Kaneko J. J. (1975) Erythrocyte enzyme activities and glutathione levels in the horse, cat, dog and man. Comp. Biochem. Physiol. 52B, 507-510.

Johnson G. B. (1974) On the estimation of effective number of alleles from electrophoretic data. Genetics 78, 771-776.

Kahn A., Cottreau D., Boyer C., Marie J., Galand C. and Boivin P. (1976) Causal mechanisms of multiple acquired red cell enzyme defects in a patient with acquired dyserythropoiesis. Blood 48, 653-662.

Komazawa M. and Oski F. A. (1975) Biochemical characteristics of young and old erythrocytes of the newborn infant. Pediatrics 87, 102-106.

Kuhnl P., Schmidtmann U. and Spielmann W. (1977) Evidence for two addition common alleles at the PGM locus. Human Genet. 35, 219-223. 
Miwa S., Fuju J., Takegawa S., Nakatsuji T., Yamato K., Ishida Y. and Ninomiya N. (1980) Seven pyruvate kinase variants characterized by the ICSH recommended methods. Br. J. Haemat. 45, 575-583.

Modiano G. (1976) Genetically determined quantitative protein variation in man, excluding immunoglobins. Attr. Accad. Naz. Lincei. Mem. Cl. Sci. fis. mat. nat., sez. III A. 13, 53-445.

Mohrenweiser H. W. (1981) Frequency of enzyme deficiency variants in erythrocytes of newborn infants. Proc. natn. Acad. Sci. U.S.A. 78, 5046-5050.

Mohrenweiser H. W. and Fielek S. (1982) Elevated frequency of carriers for triosephosphate isomerase deficiency in newborn infants. Pediatr. Res. 16, 960-963.

Mohrenweiser H. W. and Neel J. V. (1981) Frequency of thermostability variants: estimation of total "rare" variant frequency in human populations. Proc. natn. Acad. Sci. U.S.A. 78, 5729-5733.

Mohrenweiser H. W., Fielek S. and Wurzinger K. H. (1981) Characteristics of enzymes of erythrocytes from newborn infants and adults: activity thermostability and electrophoretic profile as a function of cell age. Am.J. hemat. 11, 125-136.

Morelli A., Benatti U., Gaetani G. F. and DeFlora A. (1978) Biochemical mechanisms of glucose 6-phosphate dehydrogenase deficiency. Proc. natn. Acad. Sci. U.S.A. 75, 1979-1983.
Napier J. R. and Napier P. H. (1967) A Handbook of Living Primates, p. 1. Academic Press, New York

Neel J. V., Mohrenweiser H. W. and Meisler M. M. (1980) Rate of spontaneous mutation at human loci encoding protein structure. Proc. natn. Acad. Sci. U.S.A. 77, $6037-6041$

Satoh C. and Mohrenweiser H. W. (1979) Genetic heterogeneity within an electrophoretic phenotype of phosphoglucose isomerase in a Japanese population. Ann. Hum. Genet. Lond. 42, 283-292.

Smith J. E. and Kiefer S. (1973) Comparative erythrocyte metabolism. Breed differences using canine cells. Enzyme 14, 76-81.

Smith J. E., Barnes J. K., Kaneko J. J. and Freedland R. A. (1965) Erythrocytic enzymes of various animal species. Nature, Lond. 205, 298-299.

Spencer N., Hopkinson D. A. and Harris H. (1974) Quantitative differences and gene dosage in the human red cel acid phosphatase polymorphism. Nature, Lond. 201, 299-300.

Tashian R. E. (1977) Evolution and regulation of the carbonic anhydrase isozymes. Isozymes. Curr. Topics Biol. Med. Res. 2, 21-62.

Wurzinger K. H. and Mohrenweiser H. W. (1982) Studies on the genetic and non-genetic (physiological) variation of human erythrocyte glutamic oxaloacetic transaminase Ann. Hum. Genet. 46, 19l-201. 